\title{
Changes in Hepatic Key Enzymes of Dairy Calves in Early Weaning Production Systems
}

\author{
S. Haga, ${ }^{\star 1,2}$ S. Fujimoto,† T. Yonezawa, ${ }^{\star}$ K. Yoshioka, ${ }^{*}$ H. Shingu,‡ Y. Kobayashi, ${ }^{*}$ T. Takahashi, ${ }^{*}$ Y. Otani, ${ }^{*}$ \\ K. Katoh, ${ }^{*}$ and Y. Obara* \\ *Department of Animal Physiology, Graduate School of Agricultural Science, Tohoku University, Amamiyamachi, Aoba-ku, Sendai 981-8555, \\ Japan \\ †National Livestock Breeding Center for Nagano, Arakoda, Saku, Nagano 385-0007, Japan \\ fDepartment of Animal Production and Grasslands Farming, National Agricultural Research Center for Tohoku Region, Morioka, Iwate 020- \\ 0198, Japan
}

\section{ABSTRACT}

The objective of the present study was to describe plasma hormonal and metabolite profile and mRNA expression levels and activities of the enzymes pyruvate carboxylase (PC), phosphoenolpyruvate carboxykinase (PEPCK), and acetyl-coenzyme A (CoA) carboxylase in the liver of male Holstein calves before ( 1 and $3 \mathrm{wk}$ of age) and after (8, 13, and 19 wk of age) weaning at 6 wk of age. The mean plasma concentration of acetate and $\beta$-hydroxybutyrate increased, and that of plasma lactate and nonesterified fatty acids decreased with week, particularly after weaning. Plasma glucose concentration was lowest at $8 \mathrm{wk}$ of age. The mean plasma concentration of insulin and glucagon did not change with time, and that of cortisol was greatest at $1 \mathrm{wk}$ of age. In the liver, enzyme activity of PC was greatest at $1 \mathrm{wk}$ of age and decreased with time. There was a significant relationship between the activity and the mRNA level for PC. Activity of PEPCK also decreased with week. Acetyl-CoA carboxylase activity tended to decrease with week, and activity at 13 wk of age was lower than that at other times. Expression of PC mRNA, but not that of PEPCK and acetyl-CoA carboxylase $\alpha$, decreased with week. We conclude that the hepatic gluconeogenic enzymes and acetyl-CoA carboxylase activities tend to decrease with age, reflecting changes in plasma metabolites in early weaning production systems.

Key words: calf, early weaning, gluconeogenic enzyme, liver

\footnotetext{
Received November 12, 2007.

Accepted April 9, 2008.

${ }^{1}$ Corresponding author: hagatiku@affrc.go.jp

${ }^{2}$ Present address: Grazing System Research Team, National Institute of Livestock and Grassland Science, 768, Senbonmatsu, Nasushiobara, Tochigi 329-2793, Japan.
}

\section{INTRODUCTION}

Preruminant animals have to consume glucose as the main energy source during the neonatal period. However, as the amount of lactose derived from milk fails to meet glucose demands in the body during this period, glycogenolysis and gluconeogenesis are important for carbohydrate homeostasis (Girard et al., 1992; Liggins, 1994; Hammon and Blum, 1998). After weaning, with the development of the rumen, the metabolism of carbohydrates in ruminants dramatically changes and differs in several aspects from that in preand nonruminants. In particular, ruminants are obliged to absorb only a very small amount of glucose from the intestinal tract, whereas considerable amounts of VFA, mainly acetate, propionate, and butyrate, are absorbed from the forestomach (Herdt, 1988). Nonetheless, the effect of week of age, weaning, and development of digestive functions, particularly in early weaning production systems, on metabolism of carbohydrates and physiological adaptation is not well understood in ruminants.

The liver plays a major role in the maintenance of plasma glucose homeostasis by controlling the delicate balance between hepatic glucose uptake and utilization and glucose production (Duran-Sandoval et al., 2005). In the fed state, the liver stores energy as glycogen from glucose. Conversely, when plasma glucose concentration decreases during fasting or undernutrition, the liver produces glucose through glycogenolytic and gluconeogenic pathways (Duran-Sandoval et al., 2005). These reactions are catalyzed by various enzymes, and the regulatory mechanisms for the expression of these enzymes, particularly the rate-limiting enzymes, are complex at the genetic and protein levels.

Pyruvate carboxylase (PC; EC 6.4.1.1) and phosphoenolpyruvate carboxykinase (PEPCK; EC 4.1.1.32) are rate-limiting enzymes for gluconeogenesis in the liver (Rognstad, 1979; Girard et al., 1992; Donkin, 1999). Two isozymes of PEPCK are compartmentalized in the 
Table 1. Amount and composition of milk replacer and calf starter of feed consumed (DM basis)

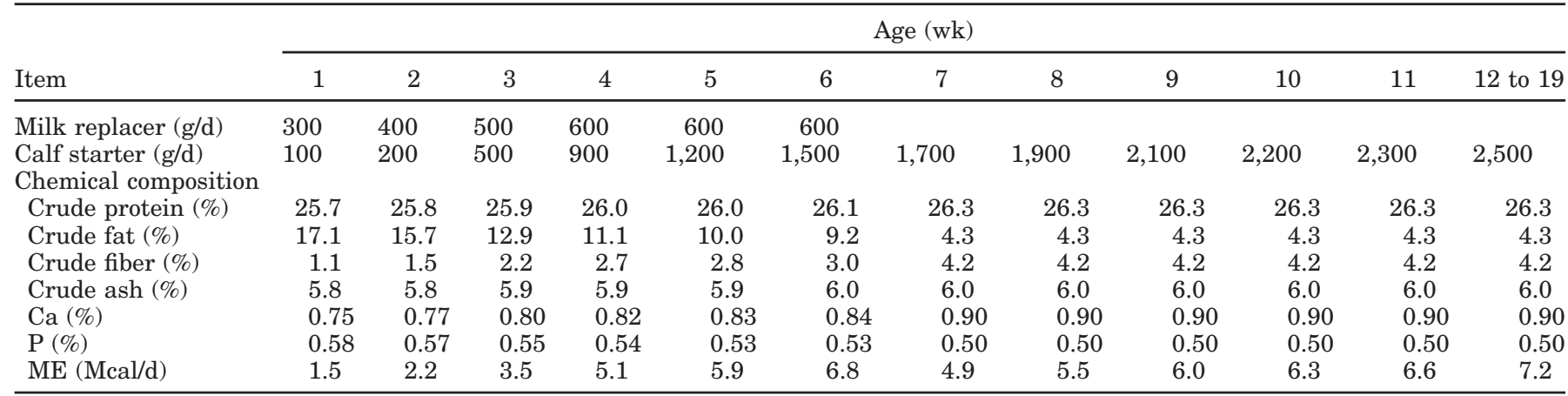

mitochondria (PEPCK-M) and cytosol (PEPCK-C). Although the relative activity within each cellular compartment differs among species (Garber et al., 1972), it has been reported that approximately equal activities of PEPCK-M and PEPCK-C are present in the ruminant liver (Taylor et al., 1971; Garber et al., 1972). Acetylcoenzyme A (CoA) carboxylase (ACC; EC 6.4.1.2) is a rate-limiting enzyme for fatty acid biosynthesis. Two isozymes of ACC, ACC- $\alpha$ and ACC- $\beta$, have been identified. Acetyl-CoA carboxylase $\alpha$ is a major rate-limiting enzyme of fatty acid biosynthesis, and ACC- $\beta$ is believed to control mitochondrial fatty acid oxidation (Kim, 1997). These enzymes are pivotal for the metabolism of carbohydrates and lipids. The objective of the present study was to describe plasma hormonal and metabolite profiles and enzyme activities and mRNA expression for PC, PEPCK, and ACC in the liver of dairy calves in early weaning production systems.

\section{MATERIALS AND METHODS}

\section{Animals and Sampling Procedures}

The present study was conducted according to the Guiding Principles for the Care and Use of Animals in the Field of Physiological Sciences (the Physiological Society of Japan, Tokyo) and was approved by the Animal Care Committee of Tohoku University. Forty-six male Holstein calves $(\mathrm{n}=8,10,10,10$, and 8 at 1,3 , 8,13 , and 19 wk of age, respectively) were slaughtered using an overdose of anesthesia (thiopental sodium, Ravonal, Tanabe Seiyaku, Osaka, Japan) without feeding in the morning (slaughter time was 1000 to 1200 h). Calves were weaned at $6 \mathrm{wk}$ of age according to a typical Japanese early weaning production system and were castrated at $11 \mathrm{wk}$ of age. Throughout the experiment, animals were fed an adequate quantity of feed according to the Japanese Feeding Standard of calves (MAFF, 1999; Kitade et al., 2002). Calves were limitfed milk replacer and calf starter (Table 1; Meiji Feed Co., Kashima, Japan). The milk replacer contained
$25.5 \% \mathrm{CP}, 21.4 \%$ crude fat, $0.1 \%$ crude fiber, $5.7 \%$ clued ash, $0.7 \% \mathrm{Ca}$, and $0.6 \% \mathrm{P}$, DM basis. Ingredients were $52 \%$ skim milk, $19 \%$ whey protein, $1 \%$ casein, $20 \%$ vegetable fat, $4 \%$ glucose and oligosaccharide, $2.1 \%$ feed additive, $1.5 \%$ emulsifier, $0.2 \%$ minerals, and $0.2 \%$ vitamins, raw materials basis, and was diluted to achieve a final DM content of $12.5 \%$. The calf starter contained $26.3 \% \mathrm{CP}, 4.3 \%$ crude fat, $4.2 \%$ crude fiber, $6.0 \%$ ash, $0.9 \% \mathrm{Ca}$, and $0.5 \% \mathrm{P}, \mathrm{DM}$ basis. Ingredients were $33 \%$ corn products, $37 \%$ soybean meal, $4 \%$ molasses, $5 \%$ rye products, $3 \%$ whey protein, $7 \%$ gluten meal, $2 \%$ barley, $1 \%$ bran, $5 \%$ apple meal, $2.2 \%$ minerals, and $0.8 \%$ vitamins, raw material basis. The milk replacer and calf starter were given to each animal in the morning (0830 h) and afternoon $(1530 \mathrm{~h})$, and all animals had free access to timothy hay, water, and mineral salts. The animals were weighed weekly, and blood samples were taken by venipuncture before the morning feeding $(0900 \mathrm{~h})$. Blood samples were centrifuged at $8,000 \times \mathrm{g}$ for $15 \mathrm{~min}$, and 5 subsamples were stored at $-30^{\circ} \mathrm{C}$ until analysis of metabolites and hormones. Blood samples for the glucagon assay were added $500 \mathrm{kIU} / \mathrm{mL}$ of aprotinin (Wako Pure Chemicals, Osaka, Japan) to avoid destruction of glucagon. Liver tissues were sampled and frozen in liquid nitrogen immediately after slaughter and stored at $-80^{\circ} \mathrm{C}$ until the measurement of the enzyme activities, mRNA levels, and glycogen and triglyceride (TG) concentrations.

\section{Blood Analyses}

Metabolites. Plasma concentrations of glucose, NEFA, and TG were determined using commercial kits (Glucose CII-Test, NEFA C-Test, and Triglyceride ETest, respectively, Wako Pure Chemicals). Plasma concentrations of acetate and BHBA were determined by UV and colorimetric methods, respectively, using F-kits (R-Biopharm AG, Darmstadt, Germany).

Hormones. Plasma concentrations of insulin and glucagon were measured by RIA as described previously (Kuhara et al., 1991). Plasma concentration of cortisol 
was measured using an ELISA kit (Oxford Biomedical Research Inc., Oxford, MI).

\section{Liver Analyses}

Analysis of Enzyme Activities. Liver segments were homogenized (multi-beads shocker, Yasui Kikai, Tokyo, Japan) in cold buffer containing $50 \mathrm{~m} M$ Tris-HCl (pH 7.4; Sigma-Aldrich, St. Louis, MO), $1 \mathrm{mM}$ EDTA (Dojindo Laboratories, Kumamoto, Japan), $15 \mathrm{mM} \mathrm{KCl,}$ $5 \mathrm{~m} M \mathrm{MgSO}_{4}, 1 \mathrm{~m} M$ dithiothreitol, $500 \mathrm{KIU} / \mathrm{mL}$ of aprotinin, and $1 \mathrm{~m} M$ phenylmethylsulfonyl fluoride fluoride (PMSF; Wako Pure Chemicals). Samples were kept on ice during the assays. The homogenates in triplicate for each sample were sonicated for $3 \mathrm{~s}$ to disrupt mitochondria and were centrifuged at $100,000 \times g$ for $20 \mathrm{~min}$ at $4^{\circ} \mathrm{C}$, and the supernatant was used for the measurement of enzymatic activities. Pyruvate carboxylase activity was assayed for $2 \mathrm{~min}$ at $25^{\circ} \mathrm{C}$ by measuring the rate of oxidation of $\mathrm{NADH}$ with a spectrophotometer at $340 \mathrm{~nm}$ in the reaction buffer containing 50 $\mathrm{m} M$ Tris- $\mathrm{HCl}(\mathrm{pH}$ 7.8):50 $\mathrm{m} M$ Tris-pyruvate $(\mathrm{pH} \mathrm{6.8})=$ 10:1 (vol/vol), $5 \mathrm{~m} M \mathrm{MgCl}_{2}, 15 \mathrm{~m} M \mathrm{KHCO}_{3}, 0.1 \mathrm{~m} M$ acetyl CoA, 0.25 mM NADH (Wako Pure Chemicals), $1 \mathrm{~m} M$ ATP, $2.63 \mathrm{U} / \mathrm{mL}$ of malate dehydrogenase (EC 1.1.1.37; Oriental Yeast Co. Ltd., Tokyo, Japan). The reaction involved the carboxylation of pyruvate to oxaloacetate (from oxaloacetate to malate with the addition of NADH and malate dehydrogenase). Phosphoenolpyruvate carboxykinase activity was assayed for $2 \mathrm{~min}$ at $30^{\circ} \mathrm{C}$ by measuring the rate of oxidation of $\mathrm{NADH}$ with a spectrophotometer at $340 \mathrm{~nm}$ in the reaction buffer containing $1 \mathrm{~m} M \mathrm{MgCl}_{2}, 1.5 \mathrm{~m} M \mathrm{MnCl}_{2}, 2 \mathrm{~m} M$ glutathione, $0.1 \mathrm{~m} M$ oxaloacetate, $0.15 \mathrm{~m} M \mathrm{NADH}$ (Wako Pure Chemicals), $3 \mathrm{~m} M$ inosin-5-triphosphate (Sigma-Aldrich), $0.66 \mathrm{U} / \mathrm{mL}$ of pyruvate kinase (PK; EC 2.7.1.40), 1.32 U/mL of lactate dehydrogenase (LD; EC 1.1.1.27; Oriental Yeast Co. Ltd.). The reaction was dependent on decarboxylation of oxaloacetate to phosphoenolpyruvate (PEP; from PEP to pyruvate) and the last reaction product (lactate) with the addition of $\mathrm{NADH}, \mathrm{PK}$, and LD (Chang and Lane, 1966; Chang et al., 1966; Maruyama et al., 1966).

The method for ACC activity analysis was described previously (Wada and Tanabe, 1983). Briefly, liver segments were homogenized in cold buffer containing 20 $\mathrm{m} M$ Tris- $\mathrm{HCl}$ ( $\mathrm{pH}$ 7.4), $2 \mathrm{~m} M$ EDTA, $0.5 \mathrm{~m} M$ ethylene glycol tetraacetic acid, $500 \mathrm{kIU} / \mathrm{mL}$ of aprotinin, and 1 mM PMSF. Samples were kept on ice during the assays, the homogenates were centrifuged at $12,000 \times g$ for $5 \mathrm{~min}$ at $4^{\circ} \mathrm{C}$, and the supernatant was used for the measurement of the enzyme activity. Acetyl-CoA carboxylase activity was assayed for $2 \mathrm{~min}$ at $37^{\circ} \mathrm{C}$ by measuring the rate of oxidation of $\mathrm{NADH}$ with a spec- trophotometer at $340 \mathrm{~nm}$ in the reaction buffer containing $50 \mathrm{~m} M$ Tris- $\mathrm{HCl}(\mathrm{pH} 7.4), 10 \mathrm{~m} M$ potassium citrate, $3.75 \mathrm{~m} M$ reduced glutathione, $0.5 \mathrm{~m} M$ potassium phosphoenolpyruvate (Wako Pure Chemicals), $0.75 \mathrm{mg} / \mathrm{mL}$ of BSA (Sigma-Aldrich), $10 \mathrm{mM} \mathrm{MgCl} 2,25$ $\mathrm{m} M \mathrm{KHCO}_{3}, 0.125 \mathrm{~m} M$ acetyl-CoA, $0.125 \mathrm{~m} M \mathrm{NADH}$, $3.75 \mathrm{~m} M$ ATP, $4.35 \mathrm{U} / \mathrm{mL}$ of PK, and $2.1 \mathrm{U} / \mathrm{mL}$ of $\mathrm{LD}$. The reaction involved the carboxylation of acetyl-CoA to malonyl-CoA (ATP + acetyl-CoA $+\mathrm{HCO}_{3}^{-} \rightarrow \mathrm{ADP}+$ phosphate + malonyl-CoA) and the conversion of PEP and ADP into pyruvate and ATP with the addition of PEP and PK (the last reaction product lactate was obtained by the addition of NADH and LD).

These enzyme activities were normalized to the protein concentration in each sample. Protein concentration in the supernatant was measured using a BCA protein kit (Pierce, Rockford, IL). All enzyme activities are expressed as units per milligram of protein. One unit was defined as the amount of enzyme that converted one nanomole of $\mathrm{NADH}$ to $\mathrm{NAD}^{+}$per minute under the assay condition.

Measurement of Glycogen and TG Content. The concentration of glycogen in the liver tissue was determined by the phenol-sulfuric acid colorimetric method (Lo et al., 1970). About $50 \mathrm{mg}$ of liver segments was homogenized in $0.4 \mathrm{~mL}$ of cold buffer containing 25 $\mathrm{m} M$ Tris- $\mathrm{HCl}(\mathrm{pH}$ 7.4) and $1 \mathrm{~m} M$ EDTA. Triglyceride content in the liver samples was extracted and quantified as described previously (Yonezawa et al., 2004).

RNA Preparation and cDNA Cloning. Total RNA was isolated from the liver tissue using NucleoSpin RNA II kit (Macherey-Nagel GmbH \& Co. KG, Düren, Germany) and was treated with RNase-free DNase (Nippon Gene Co. Ltd., Tokyo, Japan). The concentration of isolated total RNA was determined by optical density at $260 \mathrm{~nm}$ and its purity with a wavelength ratio of 260/280 nm. For cDNA cloning, $5 \mu \mathrm{g}$ of total RNA was reverse-transcribed using Super Script III (Invitrogen Corp., Carlsbad, CA).

Real-Time PCR Analysis. Real-time PCR was performed with the SYBR Premix Ex Taq (Perfect Real Time, Takara-Bio Inc., Shiga, Japan) using DNA engine Opticon 2 Continuous Fluorescence Detector (MJ Research Inc., Waltham, MA). Although reported primers were used for PEPCK-M and PC (Hammon et al., 2003), primers for PEPCK-C and ACC- $\alpha$ were newly created. The design and expected amplicon sizes of the primers are shown in Table 2. Reactions were performed in 20 $\mu \mathrm{L}$ of final volume containing $2 \times$ SYBR Premix Ex Taq, $0.3 \mu M$ primer mixtures, and $1 \mu \mathrm{L}$ from reverse-transcribed product. To reduce variability between replicates, PCR premixes containing all reagents except the template were prepared, aliquoted into $0.2-\mathrm{mL}$ thinwell plates, and subjected to PCR. The PCR conditions 
Table 2. Primers and conditions used for real-time PCR to analyze mRNA expressions of pyruvate carboxylase (PC), phosphoenolpyruvate carboxykinase (PEPCK), and acetyl-coenzyme A carboxylase (ACC) in liver

\begin{tabular}{|c|c|c|c|}
\hline Primer & Sequence & $\begin{array}{l}\text { Length } \\
\text { (bp) }\end{array}$ & Reference or accession no \\
\hline $\mathrm{PC}$ & $\begin{array}{l}\text { For }^{1}: 5^{\prime} \text {-ATCTCCTACACGGGTGACGT-3' } \\
\text { Rev }^{2}: 5^{\prime} \text {-TGTCGTGGGTGTGGATGTGCA-3' }\end{array}$ & 214 & Hammon et al., 2003 \\
\hline PEPCK-C $^{3}$ & $\begin{array}{l}\text { For: 5'-TTGGCCTCTGACCTGATCGT-3' } \\
\text { Rev: 5'-GCCATCGCAGATGTGGACTT-3' }\end{array}$ & 217 & AY145503 \\
\hline PEPCK-M ${ }^{4}$ & $\begin{array}{l}\text { For: 5'-TACGAGGCCTTCAACTGGCGT-3' } \\
\text { Rev: 5'-AGATCCAAGGCGCCTTCCTTA-3' }\end{array}$ & 365 & Hammon et al., 2003 \\
\hline ACC- $\alpha$ & $\begin{array}{l}\text { For: 5'-CCGTGCTCTGTCAGTTTCCC-3' } \\
\text { Rev: 5'-AGGTCCATCACCACAGCCTT-3' }\end{array}$ & 178 & AJ132890 \\
\hline GAPDH & $\begin{array}{l}\text { For: 5'-TCAACGGGAAGCTCACTGG-3' } \\
\text { Rev: 5'-CCCCAGCATCGAAGGTAGA-3' }\end{array}$ & 225 & Yonezawa et al., 2006 \\
\hline
\end{tabular}

${ }^{1}$ For = forward.

${ }^{2} \operatorname{Rev}=$ reverse.

${ }^{3}$ PEPCK-C = cytosolic PEPCK.

${ }^{4}$ PEPCK-M = mitochondrial PEPCK.

were 40 cycles of the following protocol; $10 \mathrm{~s}$ denaturation at $95^{\circ} \mathrm{C}$ and $20 \mathrm{~s}$ annealing at $60^{\circ} \mathrm{C}$, followed by $20 \mathrm{~s}$ extension at $72^{\circ} \mathrm{C}$. Post-PCR melting curves were observed to confirm the specificity of single-target amplification. We calculated relative mRNA expression by $2^{-\mathrm{ddCt}}$ methods, using the reference gene GAPDH. Relative mRNA expression for each enzyme was determined by calculating the difference in the cycle threshold value to that of GAPDH. We set the value at $1 \mathrm{wk}$ of age as the reference value.

\section{Statistics}

Statistical analysis was conducted with ANOVA followed by Bonferroni's multiple range test. The statistical model included week of age. The test was considered significant at $P<0.05$. The relationship between enzyme activity and the level of mRNA was determined by Pearson correlation coefficient test. All data were analyzed using Excel 2003 (Microsoft, Redmond, WA) with the add-in software Statcel 2 (Yanai, 2004).

\section{RESULTS}

\section{Body Weight}

Body weight of calves increased $(P<0.05)$ with week. Those at $1,3,8,13$, and $19 \mathrm{wk}$ of age were $46.3 \pm 1.5$ $(\mathrm{n}=8), 48.4 \pm 0.9(\mathrm{n}=10), 71.6 \pm 4.3(\mathrm{n}=10), 83.9 \pm$ $2.7(\mathrm{n}=10)$, and $117.6 \pm 3.0(\mathrm{n}=8) \mathrm{kg}$, respectively.

\section{Plasma Concentration of Hormones and Metabolites}

Metabolic Parameters. Mean concentrations of plasma acetate, BHBA, glucose, NEFA, lactate, and
TG at each week of age are shown in Table 3. Acetate concentration was under the detection limit $(0.167 \mathrm{mM})$ at 1 and 3 wk of age, increased with week, and the concentration at $13 \mathrm{wk}$ of age was greater $(P<0.05)$ than at 8 and 19 wk of age. Plasma BHBA concentration increased and reached the peak value at 13 wk of age, being about twice as high as at 8 wk of age $(P<0.05)$. Plasma glucose concentrations decreased from 1 to 8 wk of age but increased at 19 wk of age. Plasma NEFA concentration, which was maximum at $1 \mathrm{wk}$, decreased to a nadir at 13 and $19 \mathrm{wk}$ of age. After weaning at 6 wk of age, plasma lactate concentrations drastically decreased. Plasma TG concentrations were not affected during the experimental period.

\section{Hormones}

Mean concentrations of plasma insulin, glucagon, and cortisol are shown in Table 3. Plasma insulin and glucagon concentrations remained unchanged. The plasma cortisol concentration, which was at a maximum at 1 wk of age, rapidly decreased $(P<0.05)$ thereafter, and there was no difference among the mean values from 3 to $19 \mathrm{wk}$.

\section{Liver Concentration of Metabolites and Enzymes TG and Glycogen Contents in the Liver}

The TG content (Figure 1A) at $1 \mathrm{wk}$ of age was greater $(P<0.05)$ than the values observed at the other time points and rapidly decreased after 1 wk of age. The glycogen content (Figure 1B) at $19 \mathrm{wk}$ of age was greater $(P<0.05)$ than the values observed at the other time points. 
Table 3. Plasma concentrations of acetate, BHBA, glucose, NEFA, lactate, triglyceride (TG), insulin, glucagon, and cortisol around the time of weaning

\begin{tabular}{lcccccc}
\hline & \multicolumn{5}{c}{ Age (wk) } \\
\cline { 2 - 7 } Item & \multicolumn{7}{c}{1} & 3 & 8 & 13 & 19 & SEM \\
\hline Acetate $(\mathrm{m} M)$ & $\mathrm{ND}^{1}$ & $\mathrm{ND}$ & $0.210^{\mathrm{c}}$ & $0.558^{\mathrm{a}}$ & $0.410^{\mathrm{b}}$ & 0.047 \\
BHBA $(\mathrm{m} M)$ & $0.051^{\mathrm{c}}$ & $0.072^{\mathrm{bc}}$ & $0.106^{\mathrm{b}}$ & $0.222^{\mathrm{a}}$ & $0.221^{\mathrm{a}}$ & 0.018 \\
Glucose $(\mathrm{m} M)$ & $5.54^{\mathrm{a}}$ & $5.05^{\mathrm{ab}}$ & $3.49^{\mathrm{d}}$ & $4.18^{\mathrm{c}}$ & $4.90^{\mathrm{b}}$ & 0.18 \\
NEFA $(\mathrm{m} M)$ & $0.269^{\mathrm{a}}$ & $0.220^{\mathrm{ab}}$ & $0.170^{\mathrm{bc}}$ & $0.132^{\mathrm{c}}$ & $0.133^{\mathrm{c}}$ & 0.017 \\
Lactate $(\mathrm{m} M)$ & $2.81^{\mathrm{a}}$ & $2.49^{\mathrm{a}}$ & $0.675^{\mathrm{b}}$ & $0.917^{\mathrm{b}}$ & $0.883^{\mathrm{b}}$ & 0.225 \\
TG $(\mathrm{g} / \mathrm{L})$ & 0.196 & 0.189 & 0.156 & 0.171 & 0.194 & 0.007 \\
Insulin $(\mathrm{ng} / \mathrm{L})$ & 50.4 & 37.6 & 37.1 & 36.6 & 41.4 & 2.7 \\
Glucagon $(\mathrm{pg} / \mathrm{mL})$ & 264.8 & 314.0 & 281.0 & 254.3 & 305.1 & 11.9 \\
Cortisol $(\mathrm{ng} / \mathrm{mL})$ & $20.2^{\mathrm{a}}$ & $4.7^{\mathrm{b}}$ & $1.9^{\mathrm{b}}$ & $3.0^{\mathrm{b}}$ & $5.4^{\mathrm{b}}$ & 1.9 \\
\hline
\end{tabular}

${ }^{\mathrm{a}-\mathrm{d}}$ Indicate differences $(P<0.05)$ among the values at each week of age.

${ }^{1} \mathrm{ND}=$ not detected (below detection limit of $0.167 \mathrm{mM}$ ).

\section{Enzymes in the Liver}

Gluconeogenic Enzymatic Activities and mRNA Levels in the Liver. Activity of PC (Figure 2A) at 1 wk of age was greater $(P<0.05)$ than values observed at 8,13 , and 19 wk of age. Pyruvate carboxylase mRNA levels (Figure 2B) at $1 \mathrm{wk}$ were greater $(P<0.05)$ than those observed at other weeks of age. There was a linear relationship ( $\mathrm{r}=0.57, P<0.01$ ) between $\mathrm{PC}$ activity and mRNA expression (Figure 2C).

Activity of PEPCK (Figure 3A) at 1 wk of age was greater $(P<0.05)$ than that observed at other weeks, and there was also a difference $(P<0.05)$ between 3 wk and 13 and 19 wk of age. Expression of PEPCK-C mRNA (Figure 3B) at 13 wk was greater $(P<0.05)$ than those at 1, 8, and 19 wk of age. Expression of PEPCK$\mathrm{M}$ mRNA did not change with week (Figure 3C).

ACC Activity and mRNA Levels in the Liver. Acetyl-CoA carboxylase activity (Figure $4 \mathrm{~A}$ ) at 1,3 , and 8 wk was greater $(P<0.05)$ than that observed at $13 \mathrm{wk}$ of age, and ACC activity at 1 and 8 wk was also greater $(P<0.05)$ than that observed at 19 wk of age. On the other hand, there was no difference between ACC activities at 3 and $19 \mathrm{wk}$ of age. Acetyl-CoA carboxylase $\alpha$ mRNA levels (Figure 4B) did not change with week. We were not able to measure ACC- $\nu$ mRNA in the liver, because the level of expression was below the level of detection of our assay (data not shown).

\section{DISCUSSION}

In the present study, the effects of age and weaning are confounded. However, results describe changes in blood metabolites and hormones and liver enzymatic activities in calves reared in a typical intensive production system.

In our previous study, the rates of irreversible loss and recycling of glucose decreased around the time of weaning, suggesting that glucose is preferably used as the energy source in suckling calves (Hayashi et al., 2006). The glucose recycling rate in preweaning calves is greater than that in weaned calves because of the high rate of glucose use (Hayashi et al., 2006), glucose being mainly recycled via the Cori cycle (Dunn et al., 1967). Because gluconeogenesis is a part of the Cori cycle, the amount of glucose recycled via gluconeogenesis was greater at the pre- than at the postweaning period (Hayashi et al., 2006).

The concentration of plasma acetate and BHBA increased after weaning and was maintained high until $13 \mathrm{wk}$ of age. This is because calves began to absorb considerable amounts of VFA from the forestomach and to utilize VFA to meet energy demands after weaning.

Pyruvate carboxylase activity decreased with week. A similar result was also reported in Holstein calves (Hammon et al., 2005). Furthermore, we showed that PC mRNA levels also decreased with week, resulting in a significant correlation between PC activity and PC mRNA levels. Pyruvate carboxylase is one of the ratelimiting enzymes for gluconeogenesis in the liver and catalyzes the carboxylation of pyruvate to form oxaloacetate (Attwood, 1995). Because pyruvate may be formed from lactate that reaches the liver via the circulation, lactate is an important precursor for gluconeogenesis catalyzed by PC. However, in the present study, plasma lactate concentrations decreased after weaning. The main finding of the present study is that the gluconeogenetic ability of PC in the liver decreases with week, particularly after weaning. This suggestion is supported by the fact that the liver capacity to convert Llactate or pyruvate to glucose is 2 - to 3 -fold greater in pre- than in postweaning or adult sheep (Ballard and Oliver, 1965; Savan et al., 1986), that gluconeogenesis is a part of the Cori cycle pathway (Dunn et al., 1967; Hayashi et al., 2006), and that gluconeogenesis from lactate was approximately 10-fold greater in hepatocytes isolated from pre- than from postweaning calves (Donkin and Armentano, 1995). 
A

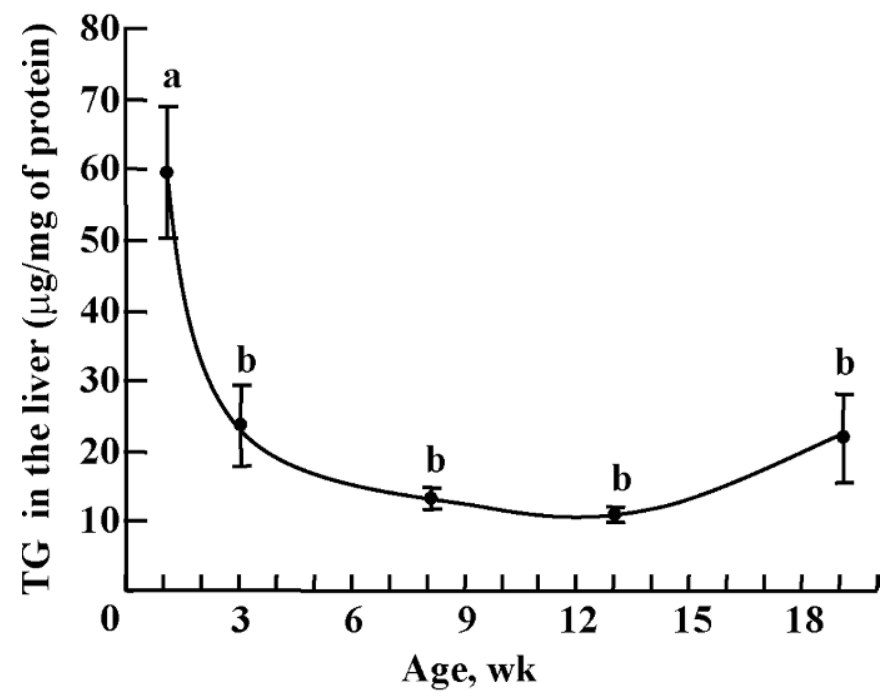

B

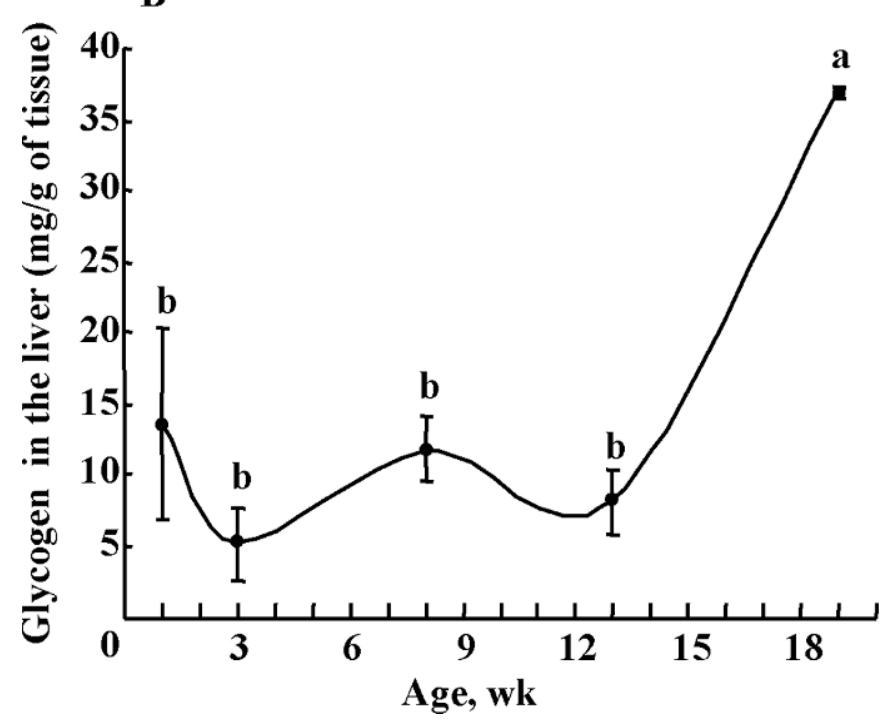

Figure 1. (A) Triglyceride (TG) and (B) glycogen contents in the liver around the time of weaning, at $1,3,8,13$, and 19 wk of age (weaning at $6 \mathrm{wk}$ of age). Values without common letters are different $(P<0.05$, Bonferroni's multiple range test).

Hammon et al. (2005) reported that cytosolic PEPCK mRNA levels increased in milk-fed calves between 7 and $42 \mathrm{~d}$ of age, whereas PEPCK enzyme activity remained unchanged, and PEPCK gene expression in milk-fed calves was not reflected by the PEPCK enzyme activities. In the present study, PEPCK-C mRNA level at $13 \mathrm{wk}$ of age was greater than those at other weeks of age. However, PEPCK activity decreased from 1 to $3 \mathrm{wk}$ and then decreased between 3 and $19 \mathrm{wk}$ of age. This indicates that there is no relationship between gene expressions and activity of PEPCK. The reason for this is not clear at present, although PEPCK-C gene
A
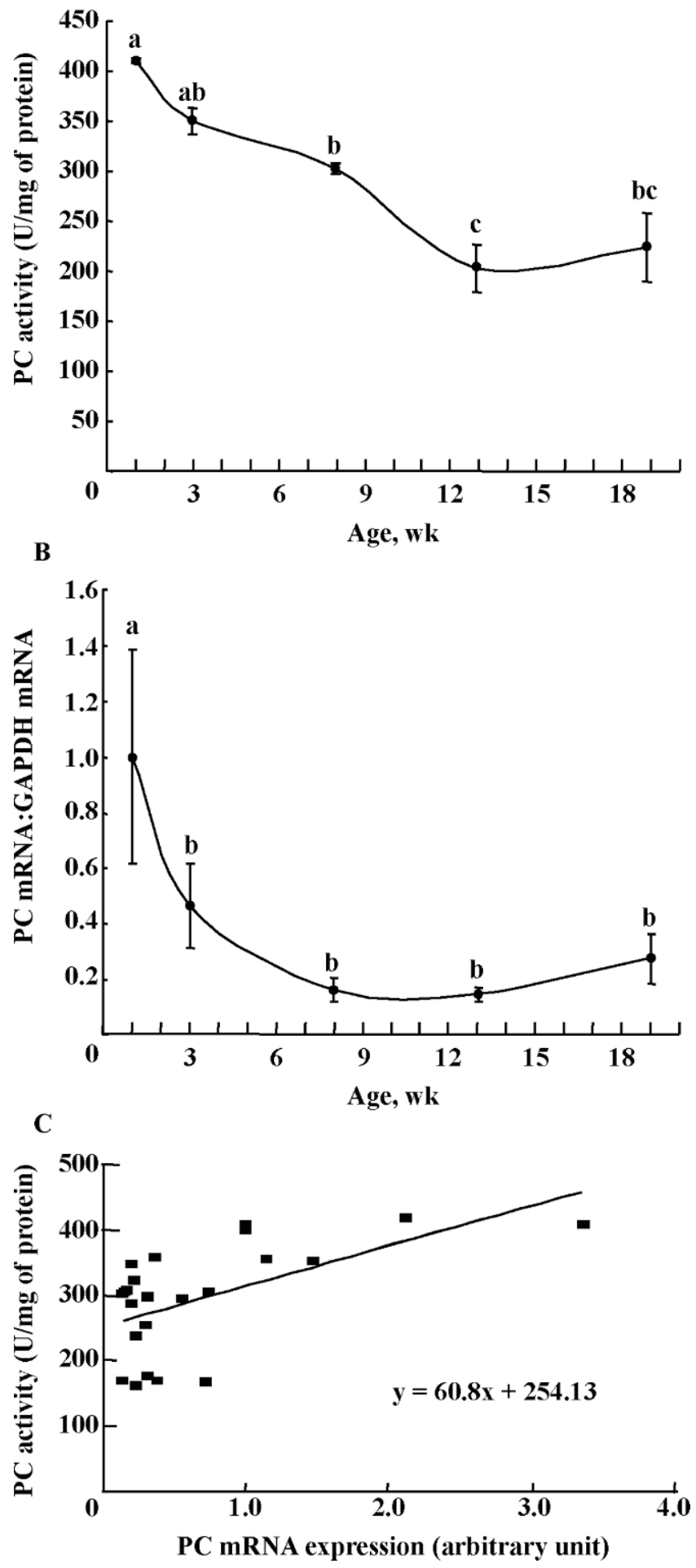

Figure 2. (A) Pyruvate carboxylase (PC) activity and mRNA levels (B) in the liver around the time of weaning, at 1, 3, 8, 13, and $19 \mathrm{wk}$ of age (weaning at $6 \mathrm{wk}$ of age). Pyruvate carboxylase mRNA level was normalized to GAPDH mRNA level. Values without common letters are different $(P<0.05$, Bonferroni's multiple range test). (C) Relationship between PC activity and PC mRNA level ( $\mathrm{y}=60.8 \mathrm{x}+$ 254.13, $\mathrm{r}=0.57, P<0.01$, Pearson's correlation coefficient test). 
A
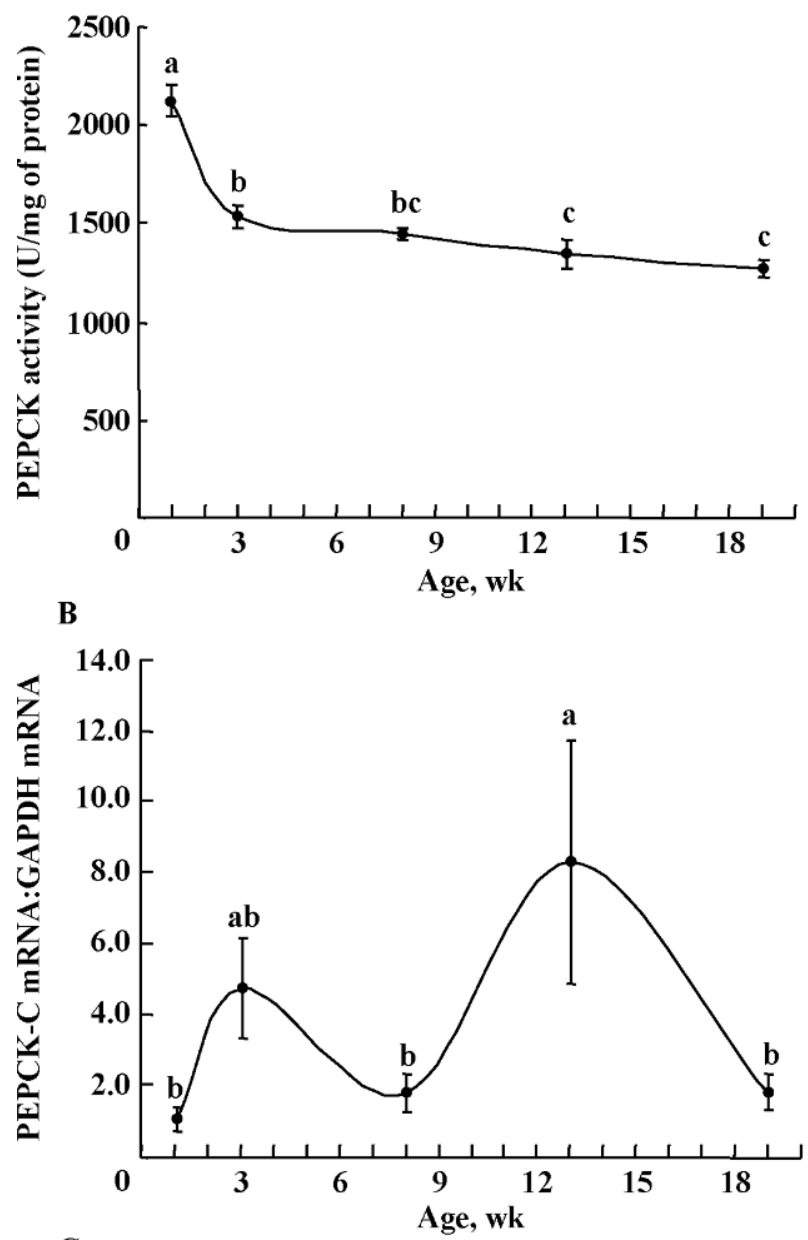

C

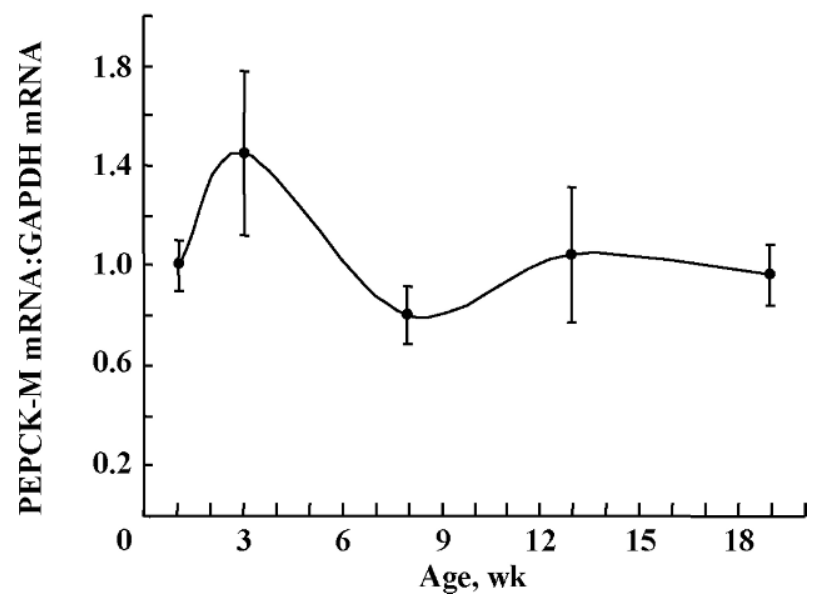

Figure 3. (A) Phosphoenolpyruvate carboxykinase (PEPCK) activity and $(\mathrm{B}, \mathrm{C}) \mathrm{mRNA}$ levels in the liver around the time of weaning, at $1,3,8,13$, and $19 \mathrm{wk}$ of age (weaning at $6 \mathrm{wk}$ of age). Phosphoenolpyruvate carboxykinase mRNA level was normalized to GAPDH mRNA level. Values without common letters are different $(P<0.05$, Bonferroni's multiple range test), and (B) PEPCK-C and (C) PEPCK$\mathrm{M}$ are cytosolic and mitochondrial forms of PEPCK, respectively.
A
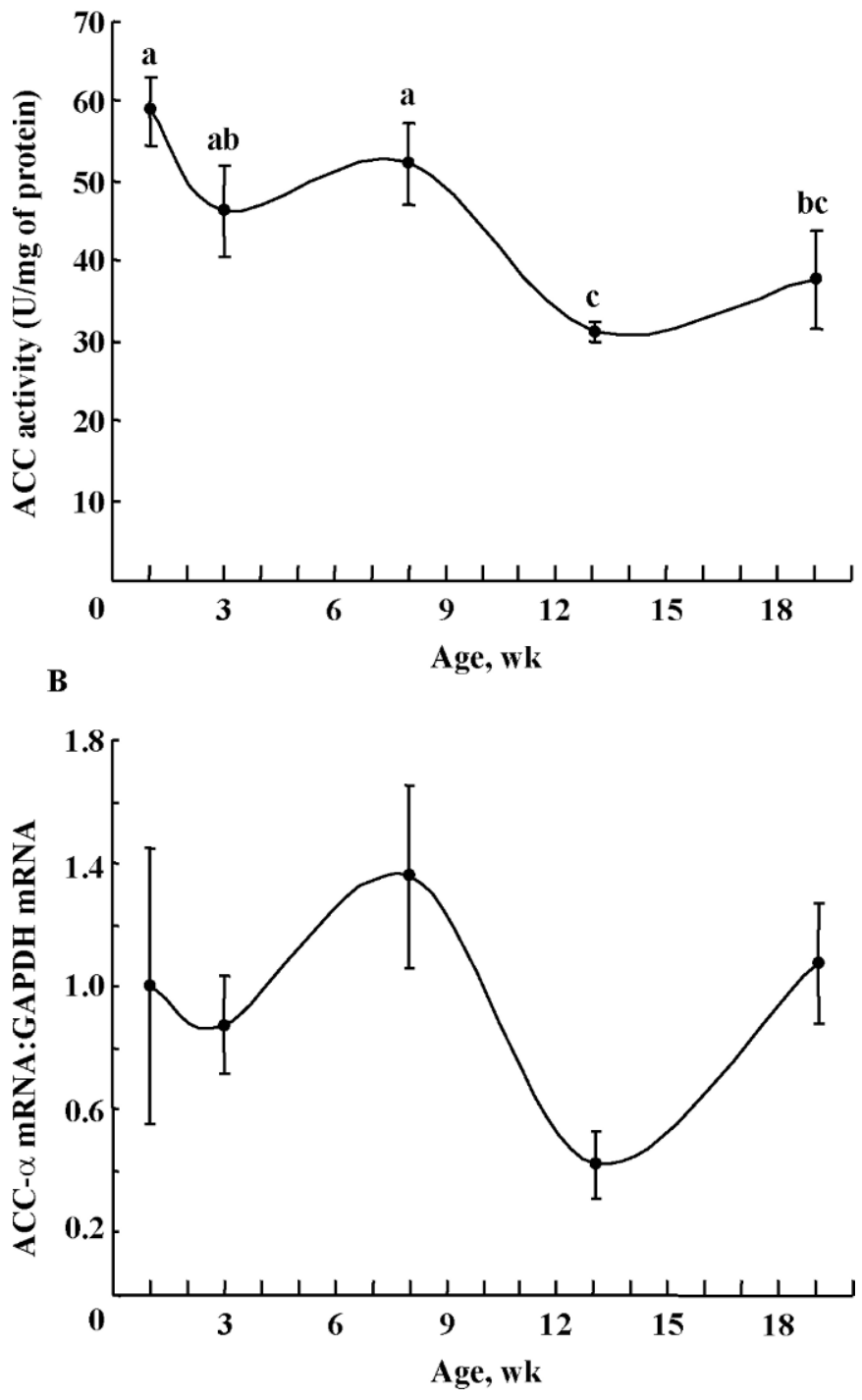

Figure 4. (A) Acetyl-coenzyme A carboxylase (ACC) activity and (B) mRNA levels in the liver around the time of weaning, at 1, 3, 8 , 13 , and $19 \mathrm{wk}$ of age (weaning at $6 \mathrm{wk}$ of age). Acetyl-coenzyme A carboxylase mRNA level was normalized to GAPDH mRNA level. Values without common letters are different $(P<0.05$, Bonferroni's multiple range test).

expression and activity have been shown to be related in mature cows during the transition to lactation (Agca et al., 2002). The activity of PEPCK in the cytosol and the mitochondria are comparable in mature cattle (Taylor et al., 1971; Garber et al., 1972) despite the greater mRNA abundance of PEPCK-C than of PEPCK-M (Agca et al., 2002).

The glycogen content in the liver at $19 \mathrm{wk}$ of age was greater than those at the other time points. The rate of glucose production and utilization in the liver and whole body was not measured in the present experi- 
ment. However, it is possible that the rate of wholebody glucose utilization and glycogenolysis in the liver of calves may decrease with week, and the storage of glycogen may increase at 19 wk of age. Furthermore, it seems that calves have adequate liver function comparable with adult ruminants in early weaning production systems.

Plasma cortisol concentration at 1 wk of age was greater than that observed at other times. The high concentration of cortisol in plasma, the so-called cortisol surge, emerges at the end of pregnancy, and it is essential for the development of normal physiological function in neonatal calves. It is known that hepatic PC and PEPCK activities are stimulated by glucocorticoids (Kraus-Friedmann, 1984; Pilkis and Granner, 1992; Jitrapakdee and Wallace, 1999). These reports support the present finding that PC and PEPCK activities at 1 wk of age are greater than at the other time points because, in part, of the high plasma cortisol concentration.

In lipogenic tissues, such as the white and brown adipose tissues and the lactating mammary gland, ACC- $\alpha$ is the major form of ACC and is highly expressed (10 to $50 \mu \mathrm{g} / \mathrm{g}$ of wet weight tissue). In oxidative tissues, such as the heart and skeletal muscle, ACC- $\beta$ is predominant but is expressed at low levels ( 1 to $2 \mu \mathrm{g} / \mathrm{g}$ of wet weight tissue). In the rat liver, where both fatty acid synthesis and oxidation are important, both types of isoforms are expressed. The greatest concentrations of ACC- $\beta$ were found in the liver, where it represented about 20 to $25 \%$ of total hepatic ACC (Abu-Elheiga et al., 1997; Munday, 2002; Brownsey et al., 2006). However, in the present study, the expression of ACC- $\beta$ mRNA was scarce in the liver, meaning that the liver may play a minor role in fatty acid oxidation in ruminants. It is also reported that the bovine is characterized by low levels of lipogenesis and a chronic low rate of secretion of very low density lipoprotein by the liver (Emery et al., 1992), and the liver in sheep contributed only $5 \%$ of the total fatty acids synthesized (Ingle et al., 1972). In the present study, ACC activity decreased with week, and the value at 13 wk of age was lower than those observed in the other weeks. At present, we are not able to explain the relationship between the decrease in ACC activity and the TG content in the liver, because the measurement method for ACC activity employed in the present study was based on the amount of malonyl-CoA produced but not on the amount of polymerized acetyl-CoA into fatty acids. However, calves likely have liver lipogenesis activity similar to adult cattle under early weaning production systems.

\section{CONCLUSIONS}

Hepatic PC, PEPCK, and ACC enzyme activities and PC mRNA level decreased, but PEPCK and ACC mRNA levels did not change with week around the time of weaning. These findings imply that hepatic gluconeogenesis of calves decreases as the rumen function develops in early weaning production systems.

\section{ACKNOWLEDGMENTS}

We gratefully thank M. T. Rose (University of Wales, Aberystwyth, UK) for his contribution in the preparation of the manuscript, the Laboratory of Animal Nutrition (Graduate School of Agricultural Science, Tohoku University, Sendai, Japan) for their cooperation on enzyme activity measurement, the Laboratory of Animal Reproduction (Graduate School of Agricultural Science, Tohoku University, Sendai, Japan) for their cooperation on sequencing of the PCR products, Feed Functionality Research Laboratory (Meiji Feed Co., Kashima, Japan) and S. Kushibiki (National Institute of Livestock and Grassland Science, Tsukuba, Japan) for their cooperation with the test animals, and T. Tayama (Laboratory of Animal Breeding and Genetics, Tohoku University, Sendai, Japan) for his helpful advice on statistical analysis.

\section{REFERENCES}

Abu-Elheiga, L., D. B. Almarza-Ortega, A. Baldini, and S. J. Wakil. 1997. Human acetyl-CoA carboxylase 2 . Molecular cloning, characterization, chromosomal mapping, and evidence for two isoforms. J. Biol. Chem. 272:10669-10677.

Agca, C., R. B. Greenfield, J. R. Hartwell, and S. S. Donkin. 2002. Cloning and characterization of bovine cytosolic and mitochondrial PEPCK during transition to lactation. Physiol. Genomics 11:53-63.

Attwood, P. V. 1995. The structure and the mechanism of action of pyruvate carboxylase. Int. J. Biochem. Cell Biol. 27:231-249.

Ballard, F. J., and I. T. Oliver. 1965. Carbohydrate metabolism in liver from foetal and neonatal sheep. Biochem. J. 95:191-200.

Brownsey, R. W., A. N. Boone, J. E. Elliott, J. E. Kulpa, and W. M. Lee. 2006. Regulation of acetyl-CoA carboxylase. Biochem. Soc. Trans. 34:223-227.

Chang, H. C., and M. D. Lane. 1966. The enzymatic carboxylation of phosphoenolpyruvate. II. Purification and properties of liver mitochondrial phosphoenolpyruvate carboxykinase. J. Biol. Chem. 241:2413-2420.

Chang, H. C., H. Maruyama, R. S. Miller, and M. D. Lane. 1966. The enzymatic carboxylation of phosphoenolpyruvate. III. Investigation of the kinetics and mechanism of the mitochondrial phosphoenolpyruvate carboxykinase-catalyzed reaction. J. Biol. Chem. 241:2421-2430.

Donkin, S. S. 1999. Role of the endocrine pancreas in animal metabolism, growth and performance. Pages 315-328 in Biology of the Pancreas in Growing Animals. S. G. Pierzynowski and R. Zabielski, ed. Elsevier, Amsterdam, the Netherlands.

Donkin, S. S., and L. E. Armentano. 1995. Insulin and glucagon regulation of gluconeogenesis in preruminating and ruminating bovine. J. Anim. Sci. 73:546-551.

Dunn, A., M. Chenoweth, and L. D. Schaeffer. 1967. Estimation of glucose turnover and the Cori cycle using glucose-6-t-14C. Biochemistry 6:6-11.

Duran-Sandoval, D., B. Cariou, F. Percevault, N. Hennuyer, A. Grefhorst, T. H. van Dijk, F. J. Gonzalez, J. C. Fruchart, F. Kuipers, and B. Staels. 2005. The farnesoid X receptor modulates hepatic 
carbohydrate metabolism during the fasting-refeeding transition. J. Biol. Chem. 280:29971-29979.

Emery, R. S., J. S. Liesman, and T. H. Herdt. 1992. Metabolism of long-chain fatty acids by ruminant liver. J. Nutr. 122:832-837.

Garber, A., F. J. Ballard, and R. W. Hanson. 1972. The significance of mitochondrial phosphoenolpyruvate formation in the regulation of gluconeogenesis in guinea pig liver. Pages 109-135 in Metabolism and the Regulation of Metabolic Processes in Mitochondria. M. A. Mehlman and R. W. Hanson, ed. Academic Press, New York, NY.

Girard, J., P. Ferré, J. P. Pégorier, and P. H. Duée. 1992. Adaptions of glucose and fatty acid metabolism during perinatal period and suckling-weaning transition. Physiol. Rev. 72:507-562.

Hammon, H., and J. W. Blum. 1998. Metabolic and endocrine traits of neonatal calves are influenced by feeding colostrum for different durations or only milk replacer. J. Nutr. 128:624-632.

Hammon, H. M., C. Philipona, Y. Zbinden, J. W. Blum, and S. S. Donkin. 2005. Effects of dexamethasone and growth hormone treatment on hepatic gluconeogenic enzymes in calves. J. Dairy Sci. 88:2107-2116.

Hammon, H. M., S. N. Sauter, M. Reist, Y. Zbinden, C. Philipona, C. Morel, and J. W. Blum. 2003. Dexamethasone and colostrum feeding affect hepatic gluconeogenic enzymes differently in neonatal calves. J. Anim. Sci. 81:3095-3106.

Hayashi, H., M. Kawai, I. Nonaka, F. Terada, K. Katoh, and Y. Obara. 2006. Developmental changes in the kinetics of glucose and urea in Holstein calves. J. Dairy Sci. 89:1654-1661.

Herdt, T. H. 1988. Fuel homeostasis in the ruminant. Vet. Clin. North Am. Food Anim. Pract. 4:213-231.

Ingle, D. L., D. E. Bauman, and U. S. Garrigus. 1972. Lipogenesis in the ruminant: In vivo site of fatty acid synthesis in sheep. J. Nutr. 102:617-624.

Jitrapakdee, S., and J. W. Wallace. 1999. Structure, function and regulation of pyruvate carboxylase. Biochem. J. 340:1-16.

Kim, K. H. 1997. Regulation of mammalian acetyl-coenzyme A carboxylase. Annu. Rev. Nutr. 17:77-99.

Kitade, K., K. Takahashi, S. Yonekura, N. Katsumata, G. Furukawa, S. Ohsuga, T. Nishita, K. Katoh, and Y. Obara. 2002. Effects of nutritional conditions around weaning on carbonic anhydrase activity in the parotid gland and ruminal and abomasal epithelia of Holstein calves. J. Comp. Physiol. [B] 172:379-385.
Kraus-Friedmann, N. 1984. Hormonal regulation of hepatic gluconeogenesis. Physiol. Rev. 64:170-259.

Kuhara, T., S. Ikeda, A. Ohneda, and Y. Sasaki. 1991. Effects of intravenous infusion of 17 amino acids on the secretion of GH, glucagon, and insulin in sheep. Am. J. Physiol. 260:21-26.

Liggins, G. C. 1994. The role of cortisol in preparing the fetus for birth. Reprod. Fertil. Dev. 6:141-150.

Lo, S., J. C. Russell, and A. W. Taylor. 1970. Determination of glycogen in small tissue samples. J. Appl. Physiol. 28:234-236.

MAFF. 1999. Japanese Feeding Standard for Dairy Cattle 1999. Japan Livestock Industry Association, Tokyo.

Maruyama, H., R. L. Easterday, H. C. Chang, and M. D. Lane. 1966. The enzymatic carboxylation of phosphoenolpyruvate. I. Purification and properties of phosphoenolpyruvate carboxylase. J. Biol. Chem. 241:2405-2412.

Munday, M. R. 2002. Regulation of mammalian acetyl-CoA carboxylase. Biochem. Soc. Trans. 30:1059-1064.

Pilkis, S. J., and D. K. Granner. 1992. Molecular physiology of the regulation of hepatic gluconeogenesis and glycolysis. Annu. Rev. Physiol. 54:885-909.

Rognstad, R. 1979. Rate-limiting steps in metabolic pathways. J. Biol. Chem. 254:1875-1878.

Savan, P. M., M. K. Jeacock, and D. A. Shepard. 1986. Gluconeogenesis in foetal, suckling, and weaned lambs: The effect of glucagon. J. Agric. Sci. 106:259-264.

Taylor, P. H., J. C. Wallace, and D. B. Keech. 1971. Gluconeogenic enzymes in sheep. Biochim. Biophys. Acta 237:179-191.

Wada, K., and T. Tanabe. 1983. Dephosphorylation and activation of chicken liver acetyl-coenzyme-A carboxylase. Eur. J. Biochem. 135:17-23.

Yanai, H. 2004. Statcel-The useful add-in software forms on Excel 2nd ed. OMS, Tokyo, Japan.

Yonezawa, T., S. Haga, Y. Kobayashi, T. Takahashi, and Y. Obara. 2006. Visfatin is present in bovine mammary epithelial cells, lactating mammary gland and milk, and its expression is regulated by cATP pathway. FEBS Lett. 580:6635-6643.

Yonezawa, T., S. Yonekura, Y. Kobayashi, A. Hagino, K. Katoh, and Y. Obara. 2004. Effects of long-chain fatty acids on cytosolic triacylglycerol accumulation and lipid droplet formation in primary cultured bovine mammary epithelial cells. J. Dairy Sci. 87:2527-2534. 